\title{
Ventilation System Design and the Coronavirus (COVID-19)
}

\author{
Alireza Afshari*, Göran Hultmark, Peter V. Nielsen and Alessandro Maccarini \\ Department of the Built Environment, Aalborg University, Copenhagen, Denmark
}

Most new office buildings in Nordic countries are equipped with balanced mechanical ventilation systems. The purpose of ventilation in office buildings is to provide thermal control by supplying cold or warm air for adequate indoor air quality. However, the role of ventilation in preventing virus transmission and maintaining a sufficient fresh air supply to obtain a low virus level through dilution is not currently well defined. Ventilation in office buildings is expected to contribute to preventing the spread of contaminants and provide comfort for occupants. The study reveals differences between risk areas for spreading airborne contaminants in office buildings in northern Europe, including Denmark, Norway and Sweden. The differences in the spread depends on different ventilation designs used

OPEN ACCESS

Edited by:

Hazim Bashir Awbi,

University of Reading,

United Kingdom

Reviewed by:

Zhang Lin,

City University of Hong Kong,

Hong Kong

Yuexia Sun,

Tianjin University, China Yong Cheng,

Chongqing University, China

*Correspondence:

Alireza Afshari

aaf@build.aau.dk

Specialty section:

This article was submitted to Indoor Environment,

a section of the journal

Frontiers in Built Environment

Received: 01 February 2021

Accepted: 31 March 2021

Published: 27 April 2021

Citation:

Afshari A, Hultmark G, Nielsen PV and Maccarini A (2021) Ventilation

System Design and the Coronavirus

(COVID-19).

Front. Built Environ. 7:662489.

doi: 10.3389/fbuil.2021.662489 in different countries.

Keywords: ventilation system, design, coronavirus, COVID-19, pressure

\section{INTRODUCTION}

Similar to influenza viruses, severe acute respiratory syndrome coronavirus 2 (SARS-CoV-2), the virus that causes the coronavirus disease 2019 (COVID-19), has the potential to cause extensive outbreaks (Occupational Safety and Health Administration, 2020). The airflow in enclosed spaces is the key factor in airborne Infectious disease transmission and is formed from the simultaneous effects of the following parameters, including heating, ventilation, and air-conditioning (HVAC) system types (e.g., displacement and mixing), HVAC installation configurations (e.g., diffusers placement and filter type), and occupant locations (e.g., distance and partitioning). Hence, the issue is whether the distance of $1.5 \mathrm{~m}$ is always appropriate for partitioning and isolating without considering the HVAC system and installation configuration. Smaller droplets can travel much more than $2 \mathrm{~m}$ away from the source and are strongly influenced by the room ventilation system and occupant activities. The literature on the risks of aerosol transmission of infection in enclosed spaces is extensive. Over 40 studies on the relationship between ventilation systems and the transmission of infection in hospitals, offices, airplanes, and ships were reviewed by Li et al. (2007).

Most new office buildings in Nordic countries are equipped with balanced mechanical ventilation systems. A ventilation system is classified as having a constant air volume (CAV) or variable air volume (VAV), depending on the airflow. The most common solutions in office buildings are VAV systems. The ventilation systems should precisely control the indoor climate; otherwise, the target values for the indoor temperature or carbon dioxide $\left(\mathrm{CO}_{2}\right)$ concentration may not be met.

Typical Nordic office environments encompass individual, small open-plan and large open-plan offices. According to a DEKAR survey, individual offices appear to be particularly common in Norwegian and Swedish enterprises. In Denmark, the structure is different; small openplan offices dominate most organizations (Bakke et al., 2007). Figure 1 depicts a small open-plan office in Denmark. 


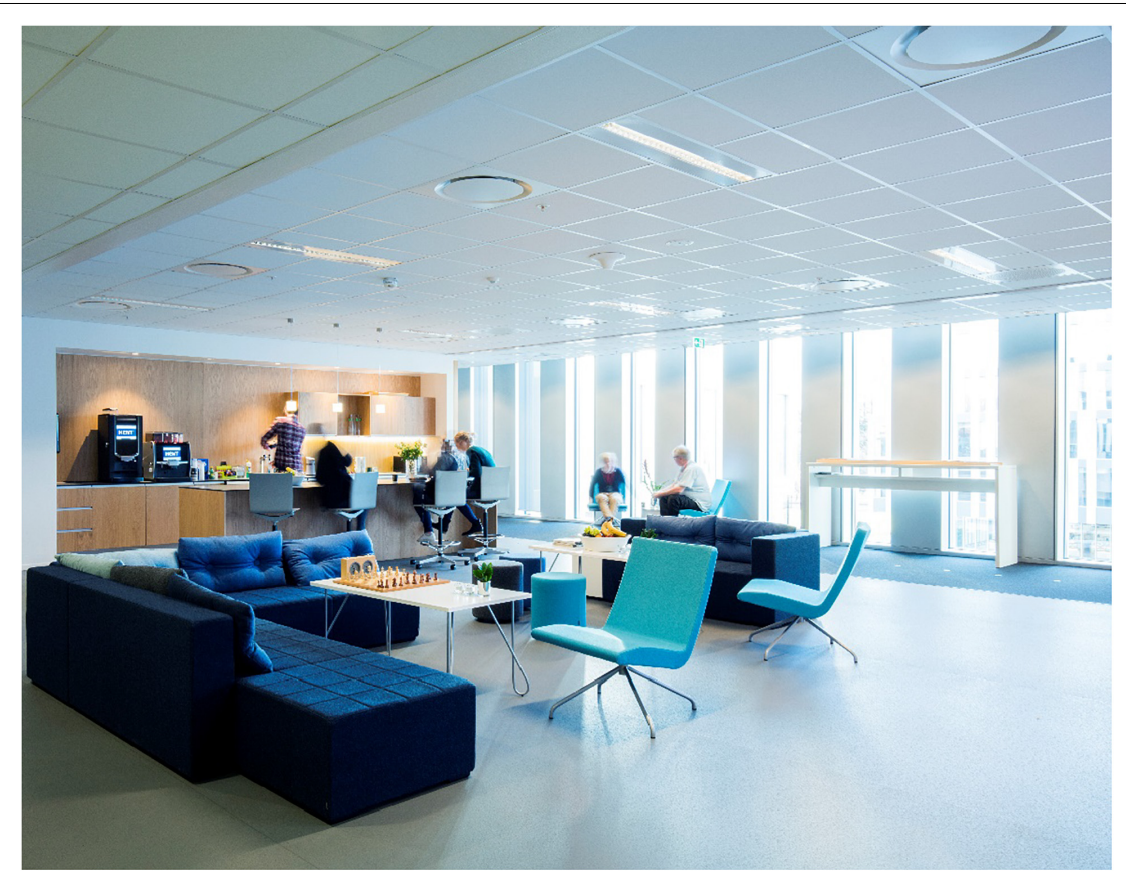

FIGURE 1 | Small open-plan office in Denmark.

The COVID-19 pandemic has changed how office buildings are used in northern Europe, including Denmark, Norway, and Sweden. Specifically, COVID-19 has affected the operation of ventilation systems. Ventilation systems are used to provide satisfactory thermal comfort and adequate indoor air quality for building occupants. Ventilation systems can be configured in various ways, depending on the applications and functions of the building. Ventilation systems provide clean air by exchanging indoor and outdoor air and by filtering.

The standard design practice regarding the indoor climate of office buildings relies on indoor comfort indices, and comfort classes quantify these subjective demands (International Organization of Standardization, 2005). However, these indices do not automatically provide satisfactory results during a pandemic, as the indoor climate in office buildings is controlled by indoor comfort and other factors.

The general difference between a pandemic and a typical situation is the health aspect. The aerosol concentration, air temperature, and relative humidity can affect health. Three transmission routes are possible for COVID-19 and many other respiratory viruses: (a) combined droplet and airborne transmission in a 1-2 $\mathrm{m}$ close-contact region arising from droplets and aerosols emitted when sneezing, coughing, singing, shouting, talking, and breathing; (b) long-range airborne (aerosol-based) transmission; and (c) surface (fomite) contact through hand-to-hand, hand-to-surface, or another route (Federation of European Heating Ventilation and Air Conditioning Associations, 2020). Aerosols are defined as droplets with nuclei smaller than 10-100 $\mu \mathrm{m}$.

The ventilation system and air distribution system influence the cross-infection risk in a room over both short and long distances between the source of infection and healthy people. For short distances, the combined droplet and aerosol flows support the transmission of the virus. The exhaled droplets $(>100 \mu \mathrm{m})$ contain water and bacteria or viruses. They are heavy and fall to horizontal surfaces at some distance shorter than 1-2 m but partly evaporate and become airborne aerosols (Xie et al., 2007). Large droplets are also influenced by air movement in the room and droplets in the range of $15-35 \mu \mathrm{m}$ move around rooms carried by the ventilation flow (Nielsen et al., 2012).

The aerosol concentration may be high with a high virus content within a short distance from an infected person. This flow in a person's microenvironment is also slightly influenced by air movement in the room (Nielsen et al., 2008; Olmedo et al., 2012). The virus from droplets and fomite transmission can be removed from surfaces by cleaning.

The ventilation system controls long-distance cross-infection risks. An infected person supplies a certain amount of virus load to the air, and the supply of fresh or filtered air controls the virus load in the room (Nielsen, 2009). It is important to keep the virus load below a certain limit depending on the disease type, an important ventilation system requirement during a pandemic.

From the outbreak reports and research studies published to date, it is not yet possible to fully determine whether aerosols result in transmission through proximity (airborne transmission), direct contact (aerosol contamination of the hands, etc.), or indirect contact (aerosol contamination of objects or surfaces). According to the current body of evidence on COVID-19, the high risk of transmission in crowded indoor settings involves both droplets and aerosols through close contact and surface contact. The importance of combining bundles 
of prevention measures has been discussed (European Centre for Disease Prevention and Control, 2020). Morawska et al. (2020) discussed and documented the possibility of long-range airborne transmission.

For instance, in Denmark, the national guidelines for HVAC systems regarding COVID-19 are the following (Sundhedsstyrelsen, 2020):

- Introduce or optimize ventilation on premises with public access (e.g., shops, offices, and public transport).

- Extend the ventilation time.

- Avoid air recirculation.

- Avoid the use of energy-saving settings or $\mathrm{CO}_{2}$ sensor controls.

In Norway, the national guidelines for HVAC systems regarding COVID-19 are the following:

- Ordinary maintenance and operation of ventilation systems are sufficient.

- In maintenance, care should be taken when changing filters to use the appropriate personal protective equipment.

- Avoid increasing further ventilation in already wellventilated rooms, which can potentially have adverse effects. The function of HVAC systems should be adapted to new working hours. The systems should be turned on around $2 \mathrm{~h}$ before the start of work and should continue to function for $2 \mathrm{~h}$ after work.

- Work positions should not be located directly under the exhaust.

- Maintaining negative pressure in toilets is recommended because aerosol formation can occur. Flushing toilets with the lid closed is also recommended.

- The guidance from the World Health Organization (WHO) and the Centers for Disease Control and Prevention (CDC) on ventilation is not practically applicable to Nordic conditions concerning the recommended degree of ventilation, indoor temperatures, and humidity.

- $\mathrm{A} \mathrm{CO}_{2}$ sensor can indicate poor air quality and the potential presence of SARS-CoV-2 from exhalation.

- The airflow rate should be maintained at $7 \mathrm{~L} / \mathrm{s}$ per person in the room, and $\mathrm{CO}_{2}$ should not exceed 1,000 ppm. The limit recommendation concerning $\mathrm{CO}_{2}$ must be balanced against the humidity (a minimum of $20 \%$ humidity in winter and $30 \%$ humidity in summer).

- If the humidity drops below $15 \%$, it may indicate that the ventilation speed is too high.

- Air purifiers are not recommended because they could create air currents.

- Ventilation measures do not replace other recommended infection control measures.

According to the European Centre for Disease Prevention and Control (2020), at present, no Swedish national guidelines exist for HVAC systems on the ventilation of indoor spaces in the context of COVID-19. Nevertheless, REHVA (2020) and American Society of Heating Refrigerating and Air-Conditioning Engineers (2020) have made several recommendations. These sources primarily deal with air change rates. However, one crucial question concerning the recommendations is whether two or more rooms situated next to each other or all individual rooms should have a balanced ventilation system to prevent room-to-room transmission of viruses. Pollutants can spread in many ways, but the focus is on airborne pollutants in this article.

The guidance from the WHO on ventilation and airconditioning systems in the context of COVID-19 indicates that steps can be undertaken to improve ventilation and air conditioning in public spaces and buildings. Operating commercial office buildings, under epidemic conditions requires a holistic framework during the crisis and restoration to a new normal after the public health emergency ends.

- Consider using natural ventilation, opening windows if it is possible and safe to do so.

- For mechanical systems, increase outdoor air percentage using economizer modes of HVAC operations, potentially as high as $100 \%$.

- Consider running the HVAC system at maximum outside airflow for $2 \mathrm{~h}$ before and after spaces are occupied.

- Increase the total airflow supply to occupied spaces, if possible.

- Disable demand-control ventilation controls that reduce air supply based on temperature or occupancy.

- Improve the central air filtration.

The CDC guidance for building ventilation systems suggests improving engineering controls using the building ventilation system, which may include some or all of the following considerations:

- Increase outdoor air ventilation using caution in highly polluted areas.

- When weather conditions allow, increase fresh outdoor air by opening windows and doors. Do not open windows and doors if doing so poses a safety or health risk (e.g., risk of falling or triggering asthma symptoms) to occupants in the building.

- Use fans to increase the effectiveness of open windows. To safely achieve this, fan placement is important and varies based on room configuration. Avoid placing fans in a way that could potentially cause contaminated air to flow directly from one person over another. One helpful strategy is to use a safely and securely placed window fan to exhaust room air to the outdoors, which helps draw fresh air into the room via other open windows and doors without generating strong room air currents.

- Decrease occupancy in areas where outdoor ventilation cannot be increased.

- Ensure ventilation systems operate properly and provide acceptable indoor air quality for the current occupancy level for each space.

- Increase airflow to occupied spaces when possible.

- Turn off any demand-controlled ventilation controls that reduce air supply based on occupancy or temperature during occupied hours. In homes and buildings where the 


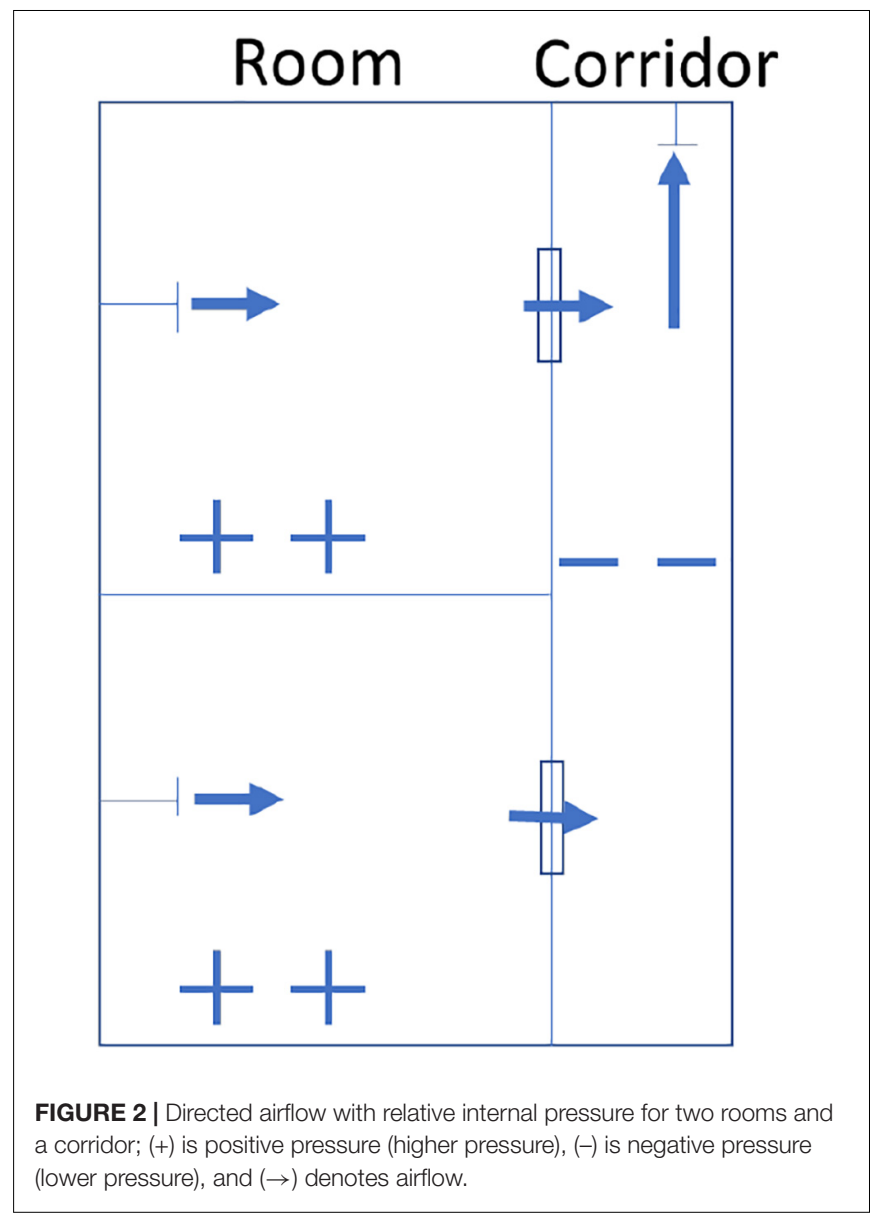

HVAC fan operation can be controlled at the thermostat, set the fan to the "on" position instead of "auto," which operates the fan continuously, even when heating or air conditioning is not required.

- Open outdoor air dampers beyond the minimum settings to reduce or eliminate HVAC air recirculation. In mild weather, this does not affect thermal comfort or humidity. However, this may be difficult to do in cold, hot, or humid weather.

- Improve central air filtration.

- Increase air filtration to as high as possible without significantly reducing the design airflow.

- Inspect filter housing and racks to ensure appropriate filter fit and check for ways to minimize filter bypass.

- Check filters to ensure they are within their service life and are appropriately installed.

- Ensure restroom exhaust fans are functional and operating at full capacity when the building is occupied.

- Inspect and maintain local exhaust ventilation in kitchens and cooking areas. Operate these systems any time these spaces are occupied. Consider operating these systems even when the specific space is not occupied to increase the overall ventilation within the occupied building.

- Consider portable high-efficiency particulate air (HEPA) fan/filtration systems to help enhance air cleaning

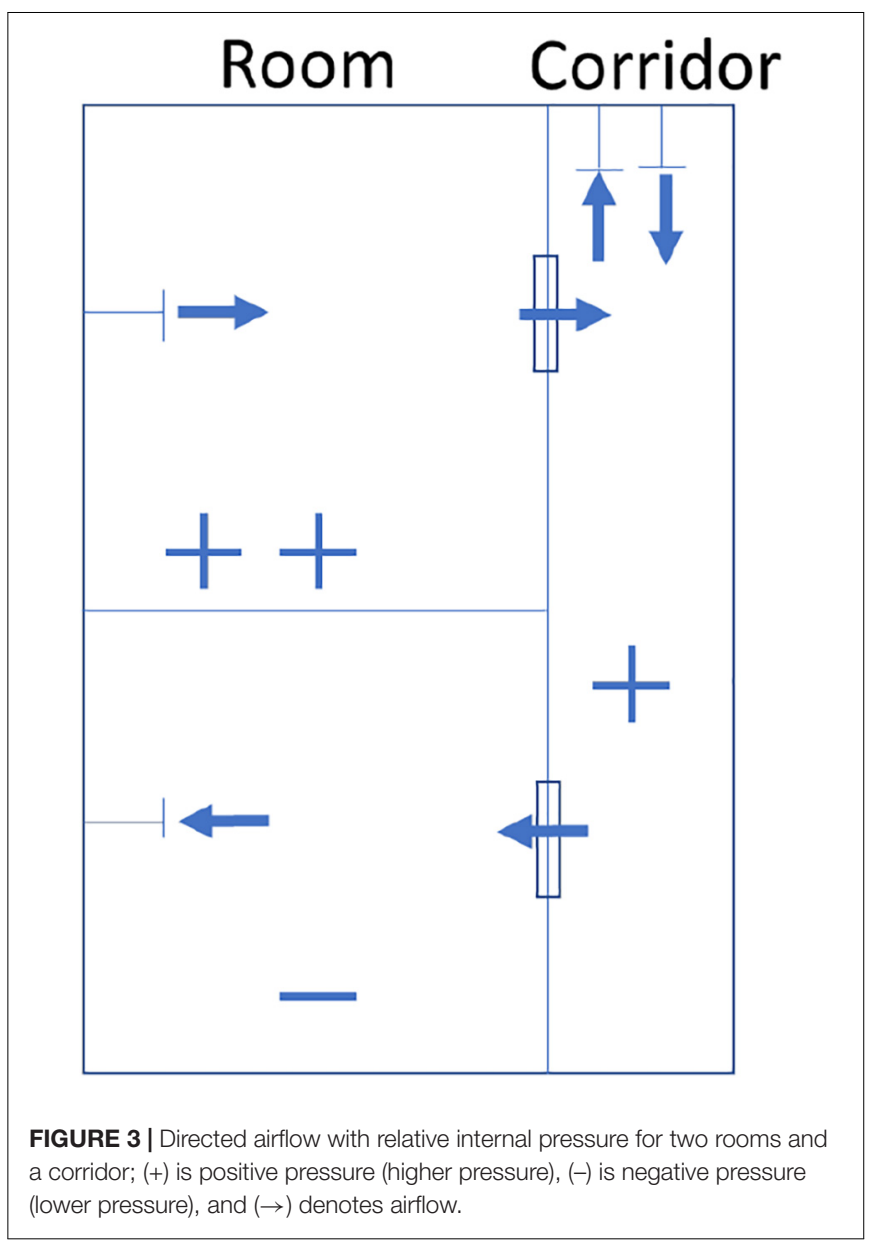

(especially in higher risk areas, such as nurses' offices or areas frequently inhabited by persons with increased risk of contracting COVID-19).

- Generate clean to less-clean air movement by re-evaluating the positioning of supply and exhaust air diffusers or dampers (especially in higher risk areas).

- Consider using ultraviolet germicidal irradiation (UVGI) as a supplement to help inactivate SARS-CoV-2, especially if options for increasing room ventilation are limited. Upper-room UVGI systems can provide air cleaning within occupied spaces, and in-duct UVGI systems can help enhance air cleaning inside central ventilation systems.

Currently, how long air remains potentially infectious inside a room occupied by someone with COVID-19 is unknown, although a systematic review and meta-analysis of SARS-CoV2 transmission found ribonucleic acid in some air sampling studies (American Institute of Architects, 2020; Chu et al., 2020). Measures to improve ventilation in an area or room where someone is ill or suspected to be ill with COVID-19 can help reduce the risk and shorten the time it takes for respiratory droplets to be removed from the air (Centers for Disease Control and Prevention, 2020). Therefore, this article aims to clarify the 
risk areas for spreading airborne contaminants in office buildings equipped with CAV or VAV in northern Europe, including Denmark, Norway, and Sweden.

\section{ROOM-TO-ROOM TRANSMISSION}

The spread of airborne pollutants depends on air movement or airflow. Two prerequisites must be fulfilled for airflow from one room to another: a pressure difference and a leakage path. If there is no pressure difference or a completely airtight wall, there is no airflow. However, in practical applications, leakage paths or open doors typically occur. Therefore, controlling the pressure difference and directing the airflow in the desired way are necessary to contain airborne contaminants. Pressure differences in buildings can be created through wind forces, temperature differences and mechanical ventilation. There must be a careful design of a mechanical ventilation system to accomplish directed airflows in a building, whereas the pressure differences created by wind and temperature are considered disturbances.

Karlsson (2008) studied the effect of wind and the stack effect on the internal pressure differences of a building in Sweden. For Swedish conditions, the simulation indicated that the wind and stack effect should not affect the desired directed airflow with an increase in the airtightness of the external wall to $0.1 \mathrm{~L} /\left(\mathrm{s} \cdot \mathrm{m}^{2}\right)$ at $50 \mathrm{~Pa}$, in an interior less-airtight wall, and a designed internal pressure difference of $15 \mathrm{~Pa}$. Furthermore, the author concluded that these external forces of wind and stack effect must first be estimate to adopt a balance between the supply and exhaust air accordingly when designing a building and ventilation system where a directed airflow is desired.

Ventilation systems can contribute to spreading contaminants in three ways from one part of a building to another: by airflow, leakage in the air-handling unit, and airflow between rooms. Only the third risk area is discussed further. For instance, different methods and technologies are available to provide adequate protection to people who work in or pass through a hospital. One of the recommended measures is to maintain negative pressure concerning the surrounding area. Negative pressure isolation rooms are for patients who require airborne droplet nuclei isolation. The aim of placing patients in negative pressure rooms is to reduce the risk of infecting other people via airborne transmission. Negative pressure prevents the air inside the patient's room from entering adjacent spaces when the door is open. Negative pressure can be achieved by controlling the quantity and quality of intake or exhaust air, maintaining different air pressures between adjacent areas, designing airflow patterns for specific clinical procedures, and diluting infectious particles with large air volumes (Saarinen et al., 2015). Differential pressure between rooms is used in hospitals and clean rooms and can be successfully implemented in offices as a temporary or permanent solution.

The design and evaluation of ventilation systems should consider such factors as the potential for room-to-room transmission when designing or modifying ventilation systems for airborne precautions. The relative pressure between the
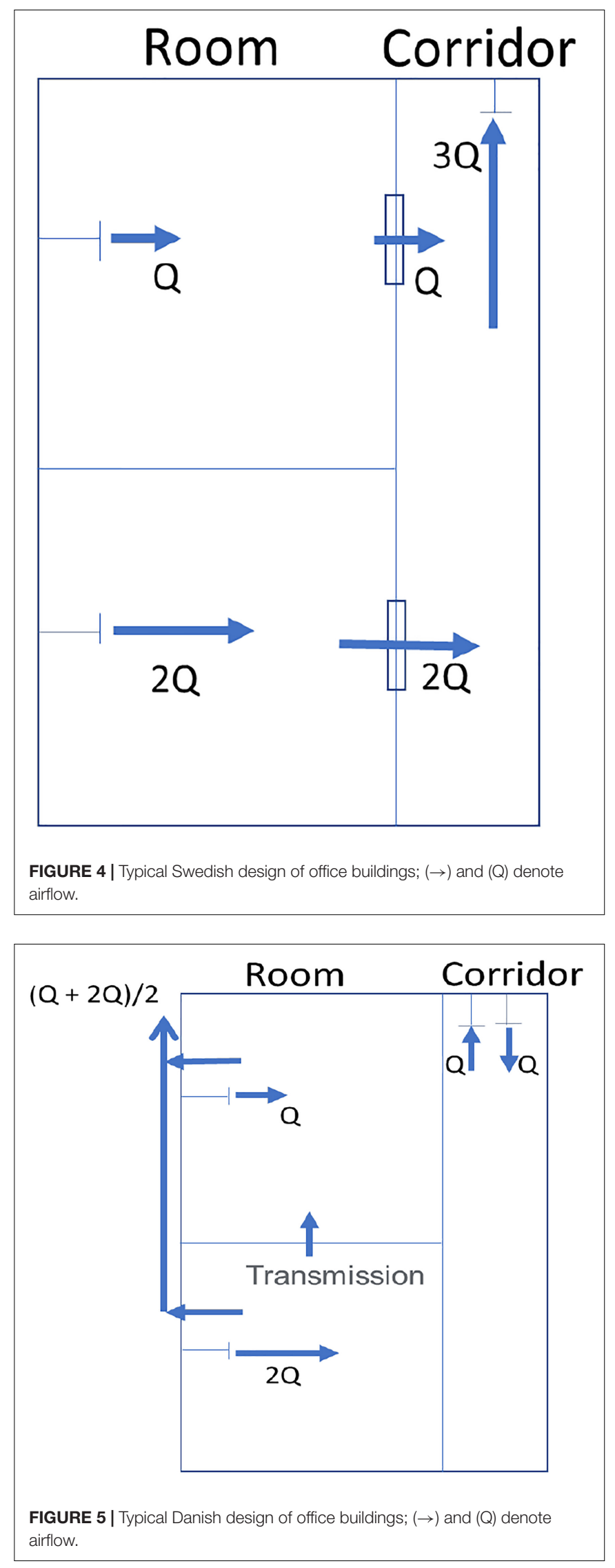


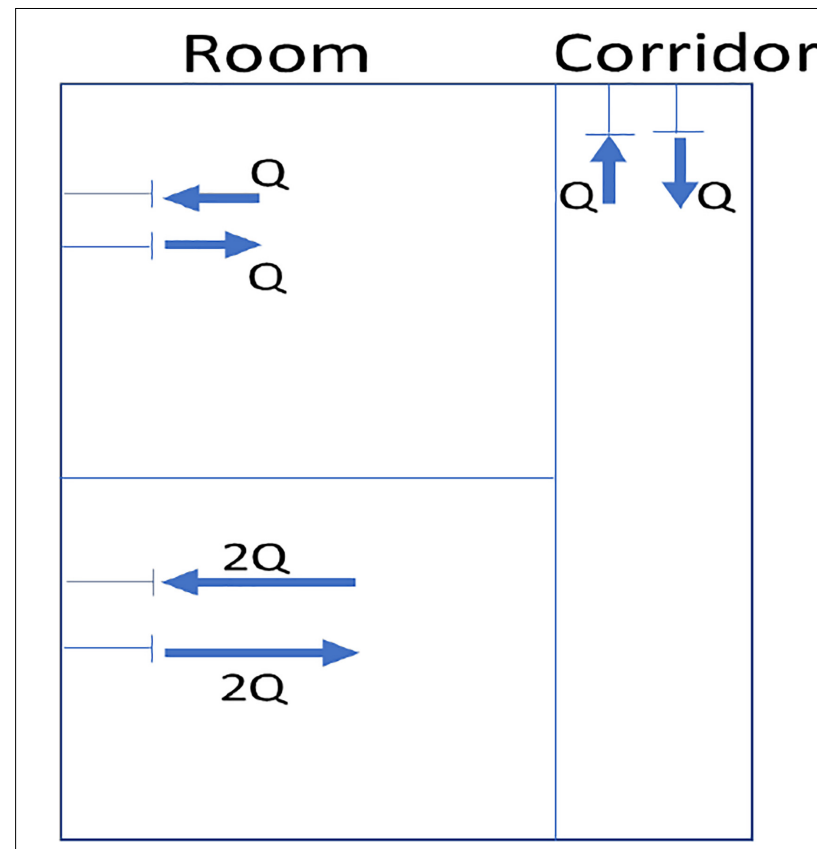

FIGURE 6 | Typical Norwegian design of office buildings; $(\rightarrow)$ and (Q) denote airflow.

rooms, airflow rate, and location of the supply and exhaust vents determine virus transmission.

According to Karlsson (2008), a mechanical ventilation system supplies and exhausts air from a room. Depending on the balance between the supplied and exhausted airflows, a mechanical ventilation system can create a pressure difference between the room and adjoining spaces, both outside and between adjacent rooms. The pressure difference depends on the airtightness of the building envelope and the interior walls and airflow balance.

Nevertheless, how mechanical ventilation affects the pressure difference is more complicated because it also depends on the ventilation balance between rooms. If one room should have a positive pressure compared to another, it is not enough that this room has more supply than exhaust air; the air surplus must be extracted in the room with lower pressure. Thus, the resulting pressure difference depends on the airflow balance both inside and between the rooms.

The main concept of avoiding pressure differences or pressurization in a room is to control the airflow direction into and out of the room. This control is achieved by controlling the flow balance between the supplied and exhausted air. However, control also requires that leakage paths are known and that some control exists regarding the airtightness of the construction.

Figure 2 illustrates the basic principle behind the directed airflow. Supplying more air than what is exhausted from the room causes surplus airflow to enter the corridor. In this figure, the relative internal pressure between the corridor and adjacent rooms is such that the corridor has negative pressure in relation to the rooms. This pressurization of a room relates to another area, which is often not realized or discussed. Therefore, it is insufficient to state that a different room has a different demand for airflow without defining it in relation to another area. A room can have both positive and negative internal pressure simultaneously in relation to a different room (Figure 3).

Therefore, when designing rooms to avoid the transmission of a virus from room to room, the pressure of these areas or rooms must be determined in relation to each other. From this determination, the correct airflow balance for each room can be established in relation to each other. Many buildings require a room or area with varying airflow demands, where the rest of the building has other airflows and air-conditioning demands. Examples of such rooms are conference rooms, small meeting rooms in offices, or server rooms for computers.

Most new office buildings in Nordic countries are equipped with balanced mechanical ventilation systems. The purpose of ventilation in office buildings is to provide thermal control by supplying cold or warm air and adequate indoor air quality. However, the role of ventilation in preventing virus transmission and maintaining a sufficient fresh air supply to obtain a low virus level through dilution is not currently well defined. Ventilation in office buildings is expected to contribute to preventing the spread of contaminants and providing comfort for occupants. Therefore, this article aims to clarify the risk areas for spreading airborne contaminants in office buildings equipped with CAV or VAV in northern Europe, including Den-mark, Norway, and Sweden.

\section{Typical Design of Swedish Office Buildings}

Transferred air is often used in Swedish offices. The air is supplied to the office rooms and transferred into the adjoining corridor, where it is exhausted (Karlsson, 2008). Special air terminal devices are used to accomplish this, allowing air to pass from the room to the corridor. These devices constitute a known opening, a controlled leakage path for the air. The existing ventilation systems in Swedish office rooms can contribute to the spread of airborne contaminants from the office room to the corridors but not to the adjacent rooms. The airflow should be supplied and exhausted from each room and corridor to avoid the spread of airborne contamination to the corridor. Other leaks, such as from the side wall and ceiling construction, must be very small. Figure 4 illustrates a typical Swedish design of office buildings.

\section{Typical Design of Danish Office Buildings}

The typical balanced ventilation system in Danish office buildings uses a supply fan to introduce the same outdoor air volume that is simultaneously removed from the house by an exhaust fan. Supply and exhaust air is installed in every room. Equal volumes of air are brought into and exhausted out of the building. However, in a room, the supplied air volume is not equal to the exhausted air volume when the supply air volume varies in a VAV system. Thus, a common exhaust is used, and the exhaust airflow rate from each room is the average airflow rate from several given rooms. Therefore, the room with a higher supplied airflow should have a positive internal pressure compared with an adjoining room, leading to surplus airflow being exhausted from the room to the adjoining room (Figure 5). The existing ventilation systems 


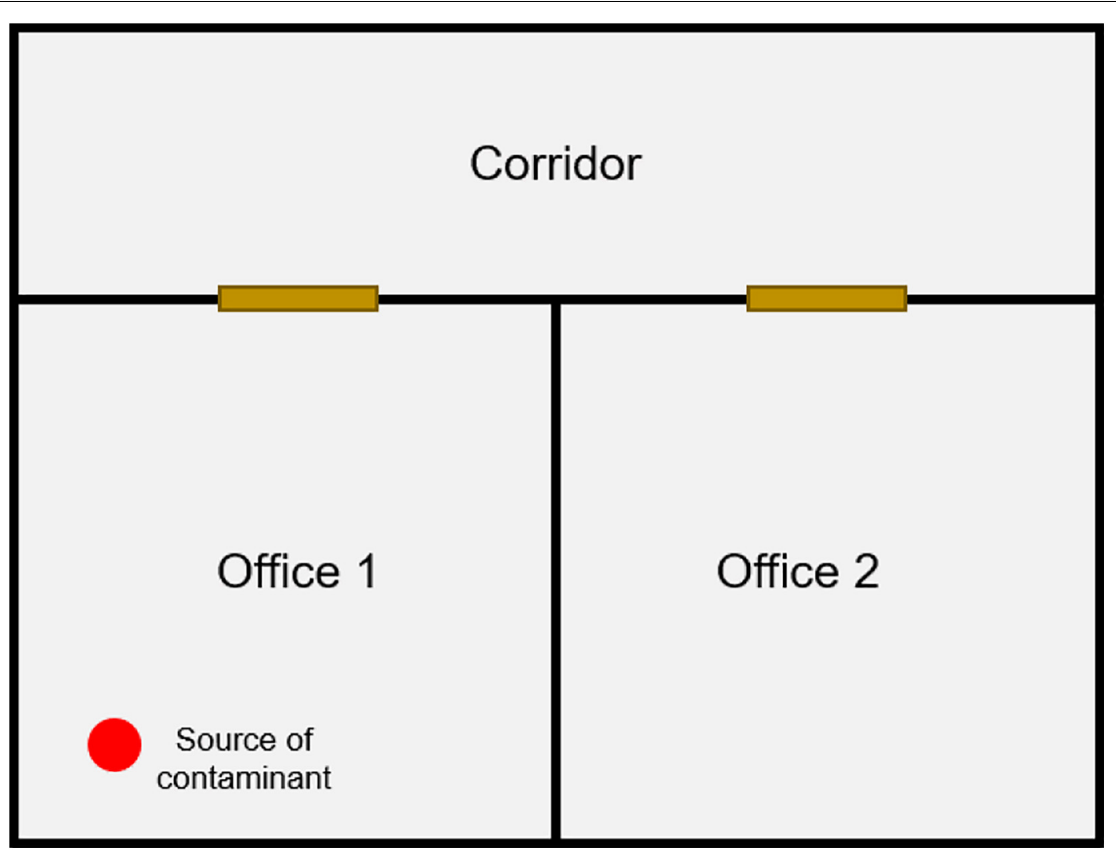

FIGURE 7 | Layout of the office space.

TABLE 1 | Ventilation rates.

\begin{tabular}{|c|c|c|c|c|c|c|c|c|}
\hline & \multicolumn{3}{|c|}{ Supply ventilation rate (I/s) } & \multicolumn{3}{|c|}{ Exhaust ventilation rate (1/s) } & \multicolumn{2}{|c|}{ Airflow through doors (1/s) } \\
\hline & Office 1 & Office 2 & Corridor & Office 1 & Office 2 & Corridor & Door 1 & Door 2 \\
\hline Sweden & 60 & 30 & 17 & 0 & 0 & 107 & 60 & 30 \\
\hline Norway & 60 & 30 & 17 & 60 & 30 & 17 & 0 & 0 \\
\hline
\end{tabular}

The negative sign for Door 2 in Denmark indicates an airflow from the corridor to Office 2.

of Danish office rooms can contribute to the spread of airborne contaminants from room to room when the room demands are different. The extracted airflow must be equal to the supplied airflow for each room to achieve the correct room pressurization.

\section{Typical Design of Norwegian Office Buildings}

In Norway, the most common ventilation system in new office buildings is the balanced-room ventilation system. In such systems, the supply and exhaust sections usually depend on each other; thus, the variation is often equal for the supply and exhaust air. This dependence cannot cause over or under pressure in the rooms (Figure 6). The existing ventilation systems in Norwegian office rooms should not spread airborne contaminants from room to room or from room to corridor, even if the room demands are different.

\section{SIMULATION STUDY}

A simulation-based study was conducted to illustrate how the ventilation system design can influence the contaminant concentration levels in indoor spaces. Three different ventilation system designs typically used in Denmark, Sweden and Norway were modeled using Modelica, a free object-oriented modeling language. Figure 7 illustrates the reference office building space considered for simulations, consisting of three zones: two single office rooms and one corridor. All three zones have the same volume $\left(27 \mathrm{~m}^{3}\right)$ but different supply ventilation rates. The zones were modeled assuming complete mixing of air. Bi-directional airflow between offices and the corridor was modelled using a door model with a leakage area of $0.02 \mathrm{~m}^{2}$ when the door is closed. Table $\mathbf{1}$ lists supply and exhaust ventilation rates for each ventilation system with the airflow passing through the doors. The calculation assumes that pollution is completely mixed in the room.

A contaminant source was introduced in Office 1 to represent the situation in which an infected person is constantly expelling an airborne virus for $9 \mathrm{~h}$ (between 8:00 and 17:00 of a typical working day). For simplicity, the contaminant considered in this study was $\mathrm{CO}_{2}$. There is increasing evidence that carbon dioxide levels in buildings correlate strongly with the airborne spread of infection (Kappelt et al., 2021). Therefore, in the present simulation, the transmission of airborne viruses was assumed 


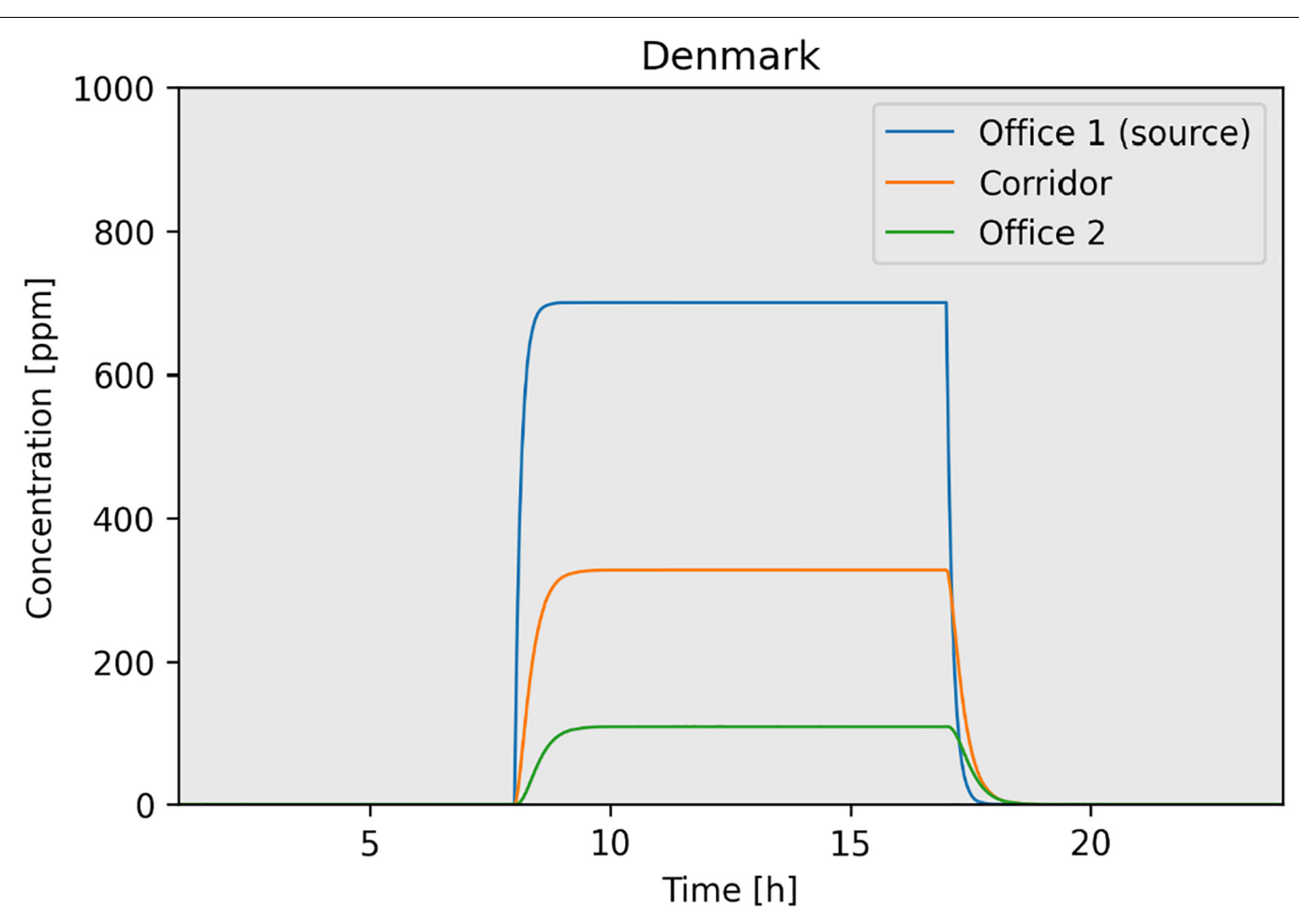

FIGURE 8 | Concentration of contaminants in typical Danish office buildings (background concentration excluded).

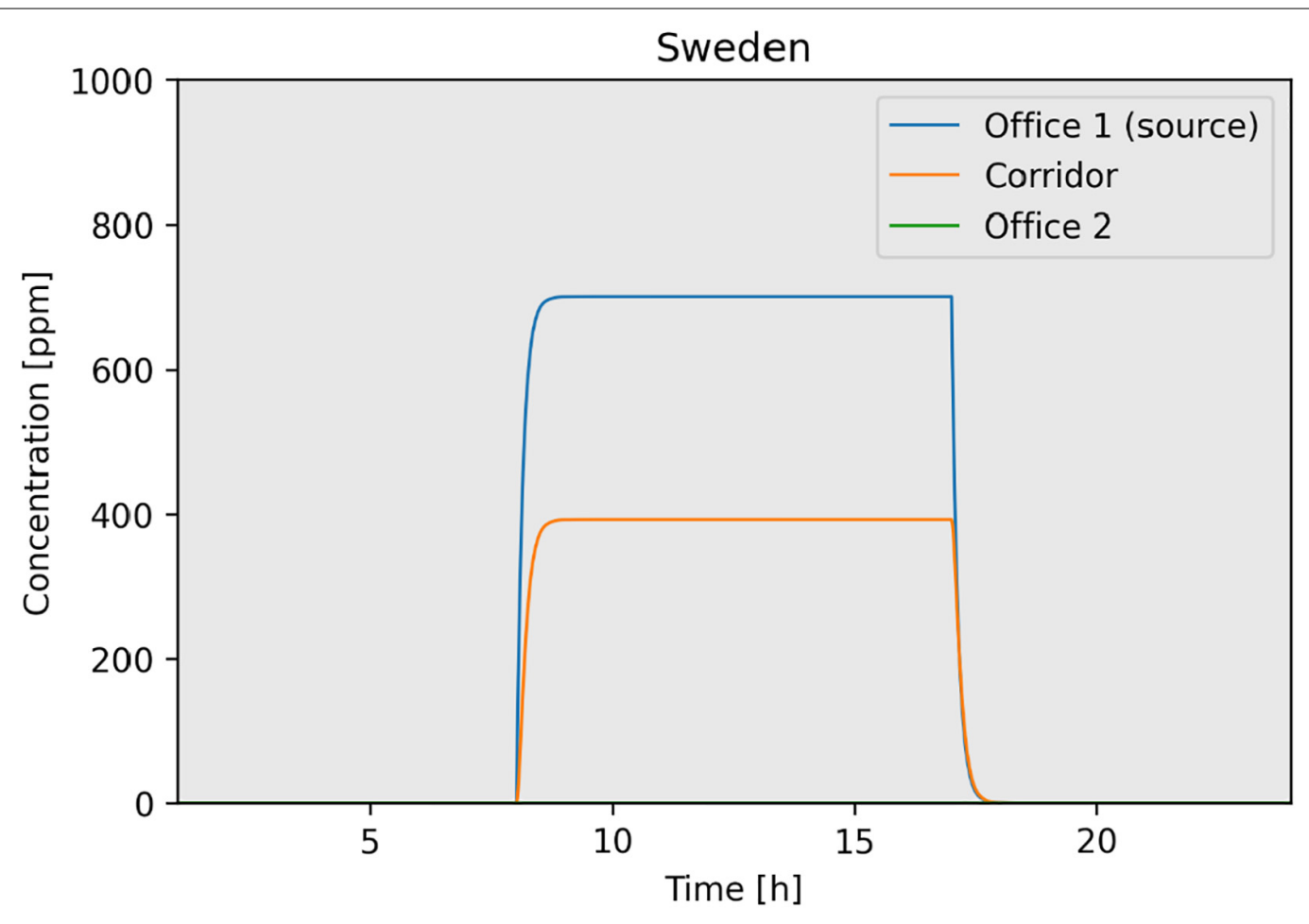

FIGURE 9 | Concentration of contaminants in typical Swedish office buildings (background concentration excluded). 


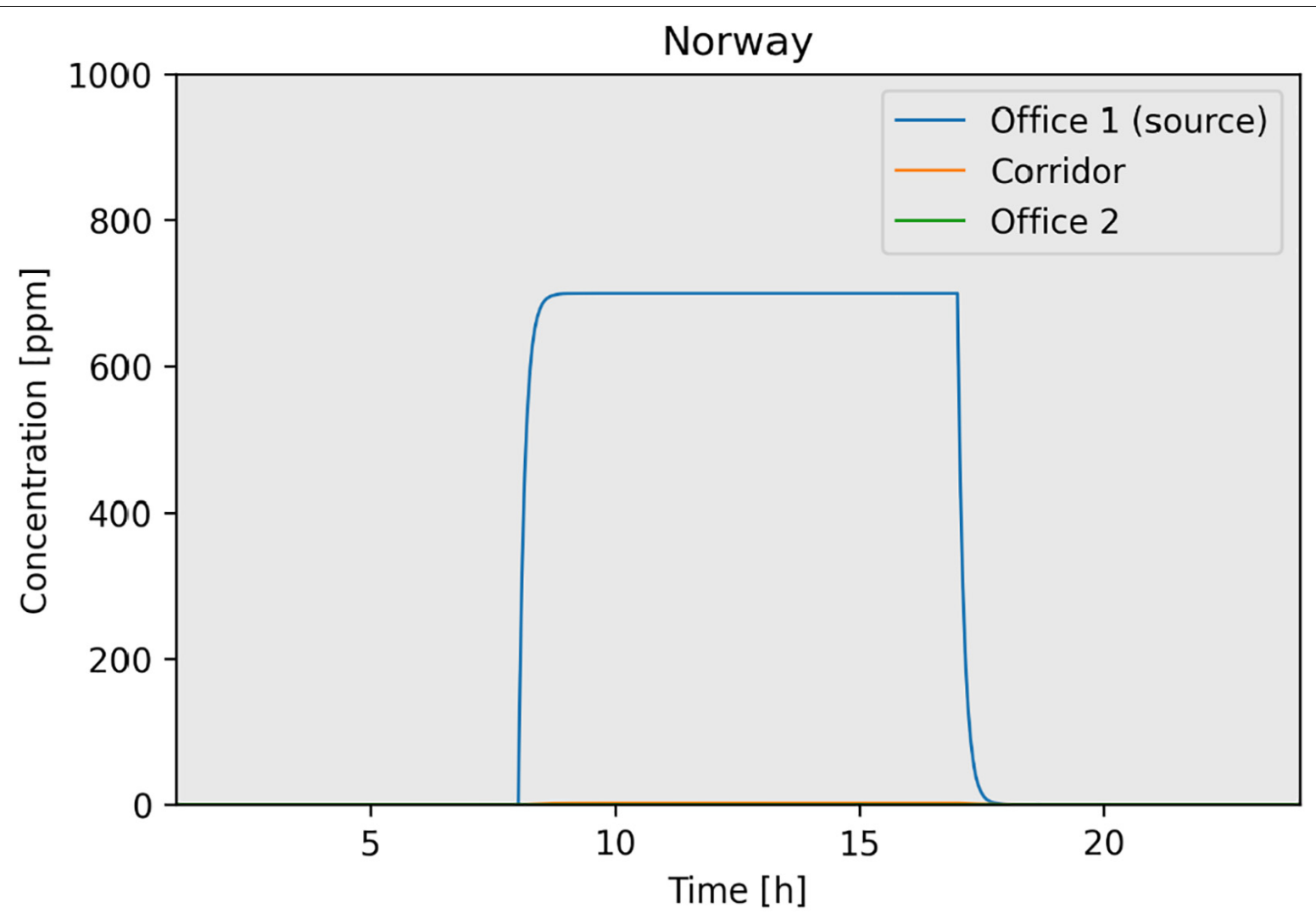

FIGURE 10 | Concentration of contaminants in typical Norwegian office buildings (background concentration excluded).

TABLE 2 | Pressure differences (Pa) across doors.

\begin{tabular}{lccccc}
\hline & \multicolumn{2}{c}{ Doors open } & & \multicolumn{2}{c}{ Doors closed } \\
\cline { 2 - 3 } \cline { 5 - 6 } & $\begin{array}{l}\text { Office 1- } \\
\text { corridor }\end{array}$ & $\begin{array}{c}\text { Office 2 } \\
\text { corridor }\end{array}$ & & $\begin{array}{c}\text { Office 1- } \\
\text { corridor }\end{array}$ & $\begin{array}{c}\text { Office 2- } \\
\text { corridor }\end{array}$ \\
\hline Denmark & 0.001 & -0.001 & & 0.4 & -0.4 \\
Sweden & 0.003 & 0.001 & & 10 & 3.5 \\
Norway & 0 & 0 & & 0 & 0
\end{tabular}

similar to that for $\mathrm{CO}_{2}$. The background concentration in the three rooms was assumed to be equal to zero at the beginning of the simulation.

Figures 8-10 present the concentration levels obtained in the three rooms for the three ventilation systems. Table 2 lists the pressure differences across the doors for two simulation cases: doors open and doors closed.

\section{CONCLUSION}

This article clarifies the risk areas for spreading airborne contaminants in office buildings in northern Europe, including Denmark, Norway, and Sweden. The following recommendations and conclusions are made. The existing ventilation systems of Swedish office rooms can contribute to spreading airborne contaminants from office rooms to corridors but not to adjacent rooms. Airflows should be supplied and exhausted from each room and each corridor to avoid spreading airborne contamination to corridors. The existing ventilation systems of Danish office rooms can contribute to spreading airborne contaminants from room to room when the room demands are different. The extracted airflows must be equal to the supplied airflows of each room to achieve the correct pressurization. The existing ventilation systems of Norwegian office rooms do not spread airborne contaminants from room to room or from room to corridor, even if the room demands are different.

\section{DATA AVAILABILITY STATEMENT}

The raw data supporting the conclusions of this article will be made available by the authors, without undue reservation.

\section{AUTHOR CONTRIBUTIONS}

AA: design of the work, drafting the work, and final approval of the version to be published. $\mathrm{GH}$ and $\mathrm{PN}$ : design of the work and drafting the work. AM: simulation study and interpretation of data for the work. All authors contributed to the article and approved the submitted version. 


\section{REFERENCES}

American Institute of Architects (2020). COVID-19 Task Force 1: Health Impact Briefing \#2. Available online at: https://content.aia.org/sites/default/files/202007/AIA_COVID_Frontline_Perspective.pdf (accessed June 22, 2020).

American Society of Heating Refrigerating and Air-Conditioning Engineers (2020). ASHRAE Position Document on Infectious Aerosols. Georgia: ASHRAE.

Bakke, J. W., Bjarnason, T., Bjerrum, E., Gunnarsdóttir, S., Hreinsdóttir, H., Julsrud, T. E., et al. (2007). Nordic Guide to Workplace Design. Nordic Innovation Centre. Available online at: http://norden.diva-portal.org/smash/ get/diva2:707118/FULLTEXT01.pdf (accessed March 29, 2021).

Centers for Disease Control and Prevention (2020). Cleaning and Disinfection for Community Facilities. Available online at: https://www.cdc.gov/coronavirus/ 2019-ncov/community/clean-disinfect/index.html (accessed March 29, 2021).

Chu, D. K., Akl, E. A., Duda, S., Solo, K., Yaacoub, S., Shünemann, H. J., et al. (2020). Physical distancing, face masks, and eye protection to prevent personto-person transmission of SARS-CoV-2 and COVID-19: A systematic review and meta-analysis. Lancet 395, 1973-1987.

European Centre for Disease Prevention and Control (2020). Heating, Ventilation and Air-Conditioning Systems in the Context of COVID-19. Available online at: https://www.ecdc.europa.eu/en/publications-data/heating-ventilation-airconditioning-systems-covid- 19.

Federation of European Heating Ventilation and Air Conditioning Associations (2020). COVID-19 guidance document. ${ }^{*}$ City publisher. Available online at: https://www.rehva.eu/fileadmin/user_upload/REHVA_COVID-19_guidance_ document_V3_03082020.pdf

International Organization of Standardization (2005). EN ISO 7730:2005. Ergonomics of the Thermal Environment - Analytical Determination and Interpretation of Thermal Comfort Using Calculation of the PMV and PPD Indices and Local Thermal Comfort Criteria (ISO 7730:2005). Available online at: https://standards.iteh.ai/catalog/standards/cen/946aa6de-6fe8-4d82a831-7f314590cc70/en-iso-7730-2005 (accessed March 29, 2021).

Kappelt, N., Johnson, M. S., Russell, H., Kwiatkowski, S., and Afshari, A. (2021). "Respiratory aerosols in correlation with metabolic $\mathrm{CO}_{2}$," in Proceeding of the European Aerosol Conference, 2021. An interactive Live Virtual Event, Hosted by the UK and Ireland Aerosol Society. (Leeds).

Karlsson, A. (2008). Ventilation System Design - A Fluid Dynamical Study With Focus on Demand Control. Ph. D, Thisis Dissertation. Sweden: Building Services Engineering, Chalmers University of Technology.

Li, Y., Leung, G. M., Tang, J. W., Yang, X., Chao, C. Y., Lin, J. Z., et al. (2007). Role of ventilation in airborne transmission of infectious agents in the built environment e a multidisciplinary systematic review. Indoor Air 17, 2-18. doi: 10.1111/j.1600-0668.2006.00445.x
Morawska, L., Tang, J. W., Bahnfleth, W., Bluyssen, P. M., Boerstra, A., Buonanno, G., et al. (2020). How can airborne transmission of COVID-19 indoors be minimised? Environ. Int. 142:105832. doi: 10.1016/j.envint.2020.105832

Nielsen, P. V. (2009). Control of airborne infectious diseases in ventilated spaces. J. R. Soc. Interface 6(Suppl. 6), S747-S755. doi: 10.1098/rsif.2009.0228.focus

Nielsen, P. V., Li, Y., Khalegi, F., Møllerskov, A., and Liu, L. (2012). “A full-scale study of exhaled droplet dispersion in the microenvironment around one and two persons," in Proceedings of the International Conference on Building Energy and Environment, Nummer 2 (Boulder, USA: University of Colorado), 1-4.

Nielsen, P. V., Winther, F. V., Buus, M., and Thilageswaran, M. (2008). Contaminant flow in the microenvironment between people under different ventilation conditions. ASHRAE Trans. 114, 632-640.

Occupational Safety, and Health Administration (2020). Guidance on Preparing Workplaces for COVID-19. OSHA 3990-03. Available online at: https://www. osha.gov/sites/default/files/publications/OSHA3990.pdf (accessed March 29, 2021).

Olmedo, I., Nielsen, P. V., Ruiz de Adana, M., Jensen, R. L., and Grzelecki, P. (2012). Distribution of exhaled contaminants and personal exposure in a room using three different air distribution strategies. Indoor Air 22, 64-76. doi: 10.1111/j.1600-0668.2011.00736.x

Saarinen, P. E., Kalliomäki, P., Tang, J. W., and Koskela, H. (2015). Large eddy simulation of air escape through a hospital isolation room single dinged doorway: validation by using tracer gases and simulated smoke videos. PLoS One 10:e0130667. doi: 10.1371/journal.pone.0130667

Sundhedsstyrelsen (2020). COVID-19: Forebyggelse af Smittespredning [Prevention of the Spread of Infection]. Available online at: https://www.sst.dk/-/ media/Udgivelser/2020/Corona/Forebyggelse-afsmittespredning/Forebyggelse -af-smittespredningpublikation.ashx?la=da\&hash=FD3E64042EEDB7A6C330 5BD37A003B5B58B1BC79 (accessed March 29, 2021).

Xie, X., Li, Y., Chwang, A. T., Ho, P. L., and Seto, W. H. (2007). How far droplets can move in indoor environments-revising the wells evaporation-falling curve. Indoor Air 17, 211-225. doi: 10.1111/j.1600-0668.2007.00469.x

Conflict of Interest: The authors declare that the research was conducted in the absence of any commercial or financial relationships that could be construed as a potential conflict of interest.

Copyright (C) 2021 Afshari, Hultmark, Nielsen and Maccarini. This is an open-access article distributed under the terms of the Creative Commons Attribution License (CC BY). The use, distribution or reproduction in other forums is permitted, provided the original author(s) and the copyright owner(s) are credited and that the original publication in this journal is cited, in accordance with accepted academic practice. No use, distribution or reproduction is permitted which does not comply with these terms. 